\title{
Estradiol promotes pentose phosphate pathway addiction and cell survival via reactivation of Akt in mTORC1 hyperactive cells
}

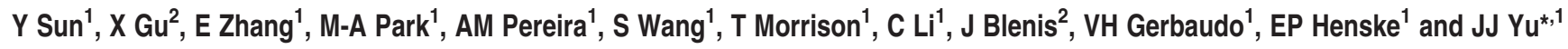

Lymphangioleiomyomatosis (LAM) is a female-predominant interstitial lung disease that can lead to respiratory failure. LAM cells typically have inactivating TSC2 mutations, leading to mTORC1 activation. The gender specificity of LAM suggests that estradiol contributes to disease development, yet the underlying pathogenic mechanisms are not completely understood. Using metabolomic profiling, we identified an estradiol-enhanced pentose phosphate pathway signature in Tsc2-deficient cells. Estradiol increased levels of cellular NADPH, decreased levels of reactive oxygen species, and enhanced cell survival under oxidative stress. Mechanistically, estradiol reactivated Akt in TSC2-deficient cells in vitro and in vivo, induced membrane translocation of glucose transporters (GLUT1 or GLUT4), and increased glucose uptake in an Akt-dependent manner. ${ }^{18} \mathrm{~F}-\mathrm{FDG}-$ PET imaging demonstrated enhanced glucose uptake in xenograft tumors of Tsc2-deficient cells from estradiol-treated mice. Expression array study identified estradiol-enhanced transcript levels of glucose-6-phosphate dehydrogenase (G6PD), the ratelimiting enzyme of the pentose phosphate pathway. Consistent with this, G6PD was abundant in xenograft tumors and lung metastatic lesions of Tsc2-deficient cells from estradiol-treated mice. Molecular depletion of G6PD attenuated estradiolenhanced survival in vitro, and treatment with 6-aminonicotinamide, a competitive inhibitor of G6PD, reduced lung colonization of Tsc2-deficient cells. Collectively, these data indicate that estradiol promotes glucose metabolism in mTORC1 hyperactive cells through the pentose phosphate pathway via Akt reactivation and G6PD upregulation, thereby enhancing cell survival under oxidative stress. Interestingly, a strong correlation between estrogen exposure and G6PD was also found in breast cancer cells. Targeting the pentose phosphate pathway may have therapeutic benefit for LAM and possibly other hormonally dependent neoplasms.

Cell Death and Disease (2014) 5, e1231; doi:10.1038/cddis.2014.204; published online 15 May 2014

Subject Category: Cancer Metabolism

Lymphangioleiomyomatosis (LAM), a rare cystic lung disease with multi-organ involvement, occurs primarily in women of childbearing age. ${ }^{1-3}$ LAM is characterized pathologically by widespread proliferation of abnormal smooth muscle cells and by cystic changes within the lung parenchyma. ${ }^{1-3}$ About $60 \%$ of women with the sporadic form of LAM also have renal angiomyolipomas. The presence of TSC2 mutations in LAM cells and renal angiomyolipoma cells from women with sporadic LAM, but not in normal tissues, has led to the hypothesis that LAM cells spread to the lungs via a metastatic mechanism, ${ }^{4}$ despite the fact that LAM cells have a histologically benign appearance. Genetic and fluorescent in situ hybridization analyses of recurrent LAM after lung transplantation support this benign metastatic model. ${ }^{4,5}$

Alterations in cellular energy metabolism are a hallmark of cancer. ${ }^{6}$ Many cancer cells generate the majority of their ATP by converting glucose to lactate, a process that was first recognized in 1930 and is referred to as the Warburg effect. ${ }^{7}$ There are several indications that cells carrying mutations in the TSC genes have defects in energy metabolism. Cells lacking TSC2 undergo massive apoptosis in glucose-free growth conditions. ${ }^{8}$ Rapamycin reduces lactate production but does not affect cellular ATP levels in Tsc2 ${ }^{-1-}$ MEF cells. ${ }^{9}$ Cells lacking Tsc1 or Tsc2 have increased expression of genes encoding the enzymes of lipid and sterol biosynthesis, glycolysis, and the pentose phosphate pathway. ${ }^{10}$ Cells with mTOR hyperactivation exhibit PKM2-stimulated glycolysis. ${ }^{11}$ Pentose phosphate pathway is a critical autophagy-dependent compensatory metabolic reprogramming in Tsc2-deficient cells. ${ }^{12}$ Despite these findings, the role of estradiol in regulating cellular metabolism in Tsc2-deficient cells has not been extensively investigated.

\footnotetext{
${ }^{1}$ Division of Pulmonary and Critical Care Medicine, Department of Medicine, Brigham and Women's Hospital and Harvard Medical School, 1 Blackfan Circle, 6th Floor, Boston, MA 02115, USA and 2Department of Cell Biology, Harvard Medical School, Boston, MA 02115, USA

*Corresponding author: JJ Yu, Division of Pulmonary and Critical Care Medicine, Brigham and Women's Hospital, Harvard Medical School, 1 Blackfan Circle, 6th Floor, Boston, MA 02115, USA. Tel: +1 617355 9018; Fax: +1 617355 9016; E-mail: jyu13@ rics.bwh.harvard.edu

Keywords: tuberin; Akt; pentose phosphate pathway; glucose transporters; glucose uptake; 6-aminonicotinamide

Abbreviations: 6-AN, 6-aminonicotinamide; ${ }^{18} \mathrm{~F}$-FDG-PET, fluodeoxyglucose positron emission tomography; ATP, adenosine triphosphate; $E_{2}, 17 \beta$-estradiol; ER, estrogen receptor; ERK, extracellular signal-regulated kinases; G6PD, glucose-6-phosphate dehydrogenase; GLUT1/4, glucose transporter1/4; $\mathrm{H}_{2} \mathrm{O}_{2}$, hydrogen peroxide; LAM, lymphangioleiomyomatosis; mTORC1, mammalian target of rapamycin complex 1; MEF, mouse embryonic fibroblasts; NADPH, nicotinamide adenine dinucleotide phosphate; PKM2, pyruvate kinase muscle isozyme 2; SCID, severe combined immunodeficiency; TBC1D7, TBC1 domain family member 7; TCGA, The Cancer Genome Atlas; TSC2, tuberous sclerosis complex 2

Received 11.1.14; revised 26.3.14; accepted 08.4.14; Edited by C Munoz-Pinedo
} 
The female predominance of LAM, coupled with the genetic data indicating that LAM cells are metastatic, suggests that estradiol may promote the metastasis of Tsc2-deficient cells. Both LAM cells and angiomyolipoma cells express estradiol receptor alpha and progesterone receptor, and the symptoms of LAM can worsen during pregnancy. ${ }^{1-3}$ Although we have previously found that estradiol promotes the survival and metastasis of Tsc2-deficient cells, the molecular and cellular mechanisms that may underlie this are not completely understood.

We report here that estradiol treatment of TSC2-deficient cells is associated with elevated levels of pentose phosphate pathway intermediates, Akt-dependent membrane translocation of the glucose transporters (GLUT1 or GLUT4), and enhanced glucose uptake in vitro and in vivo. 6-aminonicotinamide (6-AN), a competitive inhibitor of the pentose phosphate pathway, ${ }^{13}$ suppressed estradiol-induced cell survival in vitro and in vivo. Taken together, these data reveal that pentose phosphate pathway is a critical component of the estradiol-dependent cell survival of TSC2-deficient cells, and point toward novel therapeutic targets for LAM and potentially for other hormonally dependent neoplasms associated with mTORC1 activation.

\section{Results}

Identification of estradiol-induced metabolic signature of the pentose phosphate pathway in Tsc2-deficient cells. To elucidate pro-survival events mediated by estradiol $\left(E_{2}\right)$ in Tsc2-deficient rat uterus-derived ELT3 cells, ${ }^{14,15}$ we performed a metabolomics screen by LC/MS/MS. A significant increase in glycolysis and pentose phosphate pathway intermediates (Figure 1a), including glucose (3.6fold), glucose-6-phosphate (2.6-fold), fructose-6-phosphate (2.5-fold), ribose (3.6-fold), ribose-5-phosphate (2.2-fold), and ribulose-5-phosphate (2.2-fold), were observed in $E_{2}$-stimulated cells at $24 \mathrm{~h}$ (Figure 1b). Furthermore, $E_{2}$ increased the cellular levels of NADPH (Figure 1c) and decreased the levels of reactive oxygen species (ROS) (Figure 1d) in the presence or absence of hydrogen peroxide $\left(\mathrm{H}_{2} \mathrm{O}_{2}\right)$ at $24 \mathrm{~h}$. However, $\mathrm{E}_{2}$ did not affect the secretion of lactate, the end product of glycolysis (Figure 1e).

To determine the effect of $E_{2}$ in the survival of TSC2deficient cells under oxidative stress, cells were treated with
$\mathrm{H}_{2} \mathrm{O}_{2}$ or vehicle for $0.5 \mathrm{~h}$ in the presence or absence of $\mathrm{E}_{2}$ for additional $24 \mathrm{~h}$. $\mathrm{H}_{2} \mathrm{O}_{2}$-triggered cell death was strongly rescued by $\mathrm{E}_{2}$ stimulation by $26 \%(P<0.01)$ in comparison with vehicle control in LAM patient-derived cells (Figures If and $\mathrm{g}$ ). Using the $\mathrm{PI}$ exclusion assay, $\mathrm{E}_{2}$ significantly reduced $\mathrm{H}_{2} \mathrm{O}_{2}$-induced cell death by $50 \%(P<0.01)$ relative to control in rat-derived cells (Figures $1 \mathrm{~h}$ and $\mathrm{i})$. These data suggest that $E_{2}$ enhances the survival of ELT3 cells particularly under conditions of oxidative stress. Collectively, these data indicate that $E_{2}$ promotes pentose phosphate pathway addiction in cells lacking TSC2 (Figure 1j).

\section{Estradiol reactivates Akt in TSC2-deficient cells in vitro} and in vivo. To define signaling events that potentially mediate $\mathrm{E}_{2}$-enhanced glucose metabolism, we examined the activation of Akt and ERK1/2, which are known signaling molecules influenced by $E_{2}$. Under basal conditions, levels of phospho-Akt S473 were lower in TSC2-deficient LAM patient-derived cells relative to TSC2-addback cells (Figure 2a), as expected. Interestingly, $\mathrm{E}_{2}$ strongly reactivates Akt (S473) at $1 \mathrm{~h}$ and sustains Akt activation to $24 \mathrm{~h}$ in TSC2-deficient LAM patient-derived cells (TSC2 -) (Figure 2b). We also found that $E_{2}$ activates ERK1/2 (T202/Y204), as expected. In contrast, $E_{2}$ modestly stimulates Akt at $1 \mathrm{~h}$ to $8 \mathrm{~h}$ in TSC2-re-expressing cells (TSC2 +) (Figure 2c). Notably, $\mathrm{E}_{2}$ did not further enhance phosphorylation of ribosomal protein S6 (S6) (S235/236) (Figures 2b and c). Next, we examined Akt activation in Tsc2-deficient ELT3 cells, and found that $E_{2}$ stimulation resulted in a biphasic activation of Akt at 15-30 min and $6 \mathrm{~h}$ in vitro (Figure $2 \mathrm{~d}$ ). $\mathrm{E}_{2}$ also induced a biphasic activation of ERK1/2, as previously reported. ${ }^{16-18}$

To assess the effect of $E_{2}$ in Akt activation in vivo, we subcutaneously inoculated ELT3 cells into ovariectomized female SCID mice supplemented with $E_{2}$ or placebo. $E_{2}$ treatment led to a 2.3-fold increase of tumor volume at 8 weeks post cell inoculation (Figure 2e). Immunoblotting analysis showed that xenograft tumors from $E_{2}$-treated mice have higher levels of phospho-Akt (S473) and phospho-ERK (T202/Y204) compared with placebo treatment (Figure 2f). Moreover, immunohistochemical staining showed that xenograft tumors from $\mathrm{E}_{2}$-treated mice exhibit higher levels of phospho-Akt (Ser473) relative to the placebo treatment (Figure 2g). Because Tsc2-deficient cells exhibit low Akt

\footnotetext{
Figure 1 Identification of estradiol-induced metabolic signature of pentose phosphate pathway in Tsc2-deficient cells in vitro. (a) ELT3 (Tsc2-deficient rat uterus-derived) cells were treated with estradiol $(10 \mathrm{nM})$ for 2 and $24 \mathrm{~h}$. Cellular metabolites were profiled by mass spectrometry $(n=5)$ (Metabolon LC-MS/MS). (b) Box-plots of glucose, glucose-6phosphate, fructose-6-phophate, ribose, ribose-5-phosphate, and ribulose-5-phosphate are shown. Data show the mean of five sets of independent samples. (c) Cellular NADPH levels were measured in rat-derived Tsc2-deficient cells treated with control or estradiol $(10 \mathrm{nM})$ for 2 and $24 \mathrm{~h}$. Data were normalized to total protein level. Results are representative of three sets of independent samples per group from three experiments. (d) Cellular ROS levels were measured using DCFH-DA in rat-derived Tsc2-deficient cells treated with control or estradiol $(10 \mathrm{nM})$ for $24 \mathrm{~h}$. Cells were incubated with hydrogen peroxide $\left(\mathrm{H}_{2} \mathrm{O}_{2}\right)(0.5 \mu \mathrm{M})$ for $1 \mathrm{~h}$ before measurement. Data were normalized to total cell number. Results are representative of eight independent samples per group from three experiments. (e) Extracellular lactate levels were measured in rat-derived Tsc2-deficient cells treated with control or estradiol $(10 \mathrm{nM})$ for $24 \mathrm{~h}$. FBS $(10 \%)$ stimulation was included as a positive control. Lactate levels were normalized to total proteins. Results are representative of three sets of independent samples per group from three experiments. (f) Patient-derived TSC2-deficient cells were treated with control or estradiol ( $10 \mathrm{nM})$ for $24 \mathrm{~h}$, and then incubated with hydrogen peroxide $(0.5 \mu \mathrm{M})$ for $0.5 \mathrm{~h}$. Cell morphology was recorded using phase-contrast microscopy. (g) Patient-derived TSC2-deficient cells were treated with control or estradiol $(10 \mathrm{nM})$ for $24 \mathrm{~h}$, and then incubated with $\mathrm{H}_{2} \mathrm{O}_{2}(0.5 \mu \mathrm{M})$ for $0.5 \mathrm{~h}$. Cell death was measured using the propidium iodide (PI) exclusion assay. Proportion of dead cells was normalized to the total number of variable cells. Results are representative of eight independent samples per group from three experiments. (h) Rat-derived Tsc2-deficient cells were treated with control or estradiol $(10 \mathrm{nM})$ for $24 \mathrm{~h}$, and then incubated with hydrogen peroxide $(0.5 \mu \mathrm{M})$ for $1 \mathrm{~h}$. Cell morphology was recorded using phase-contrast microscopy. (i) Rat-derived Tsc2-deficient cells were treated with control or estradiol $(10 \mathrm{nM})$ for $24 \mathrm{~h}$, and then incubated with $\mathrm{H}_{2} \mathrm{O}_{2}(0.5 \mu \mathrm{M})$ for $1 \mathrm{~h}$. Cell death was measured using the PI exclusion assay. Proportion of dead cells was normalized to the total number of variable cells. Results are representative of eight independent samples per group from three experiments. (j) Scheme of glucose metabolism in TSC2-deficient cells treated with estradiol. ${ }^{\star} P<0.05,{ }^{\star \star} P<0.01$
} 


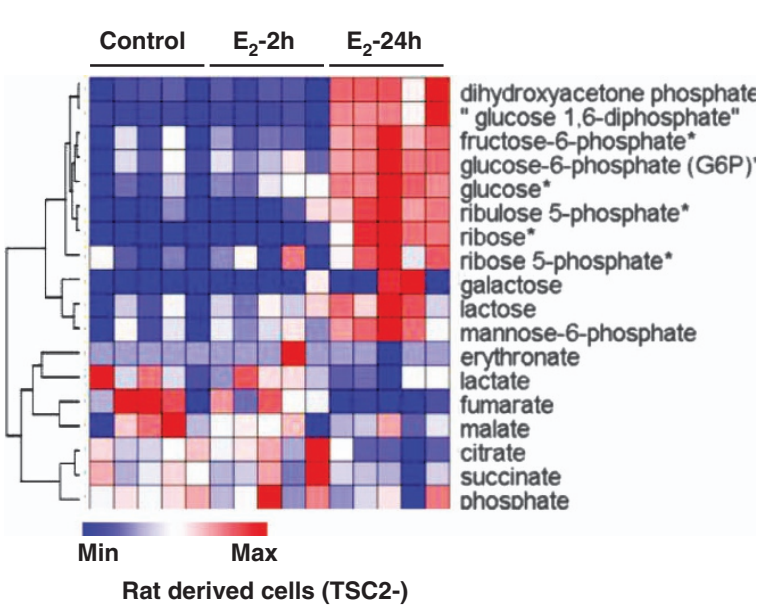

d

C

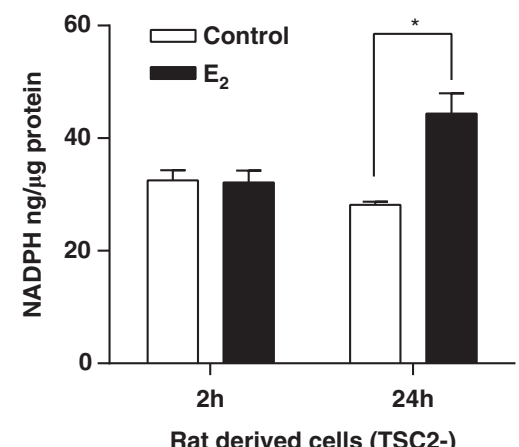

b
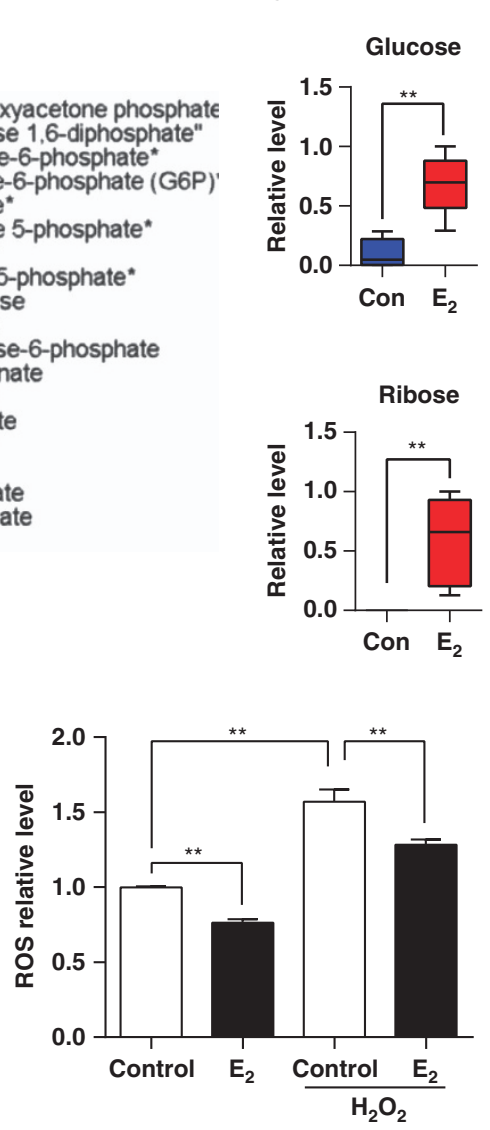

Rat derived cells (TSC2-)
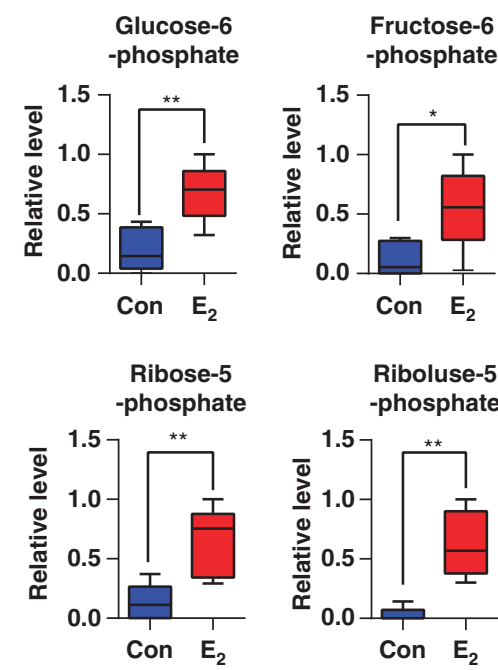

Riboluse-5

-phosphate
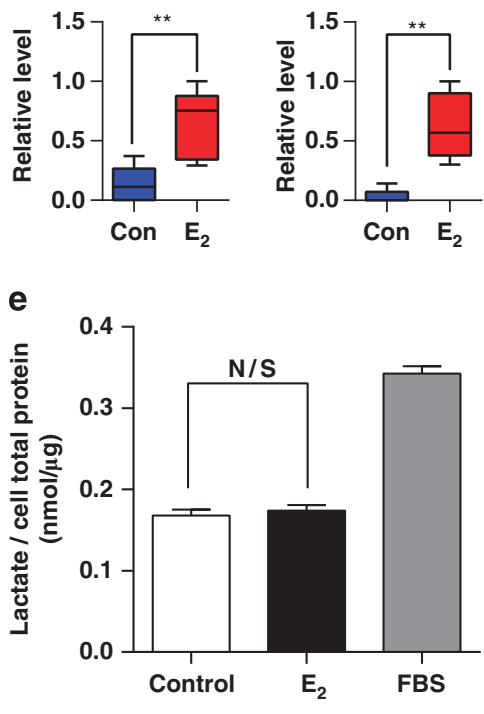

Rat derived cells (TSC2-)

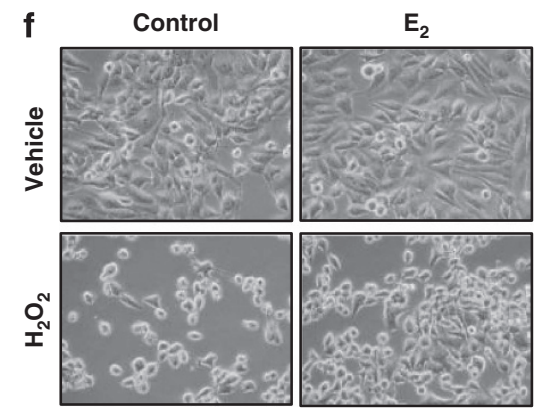

Patient derived cells (TSC2-)

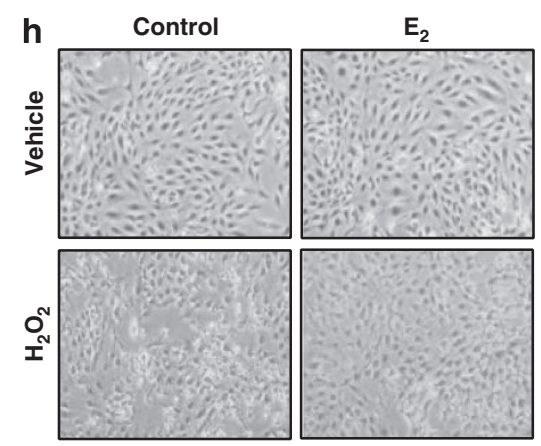

Rat derived cells (TSC2-)

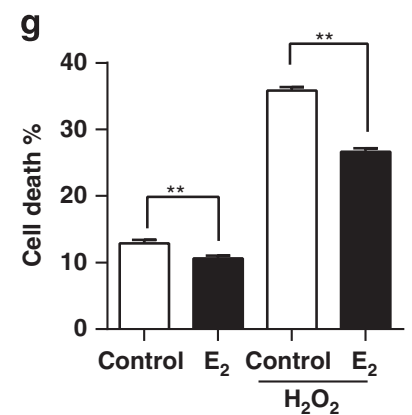

Patient derived cells (TSC2-)

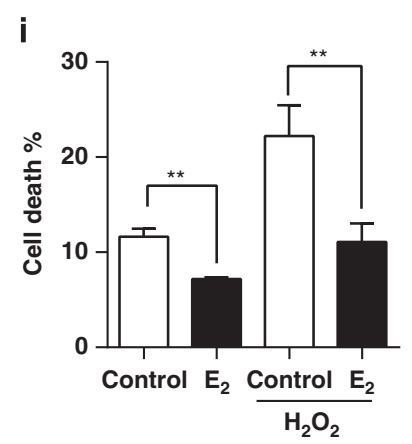

Rat derived cells (TSC2-)

j

\section{$E_{2} \rightarrow$ Glucose metabolism \\ Glucose}

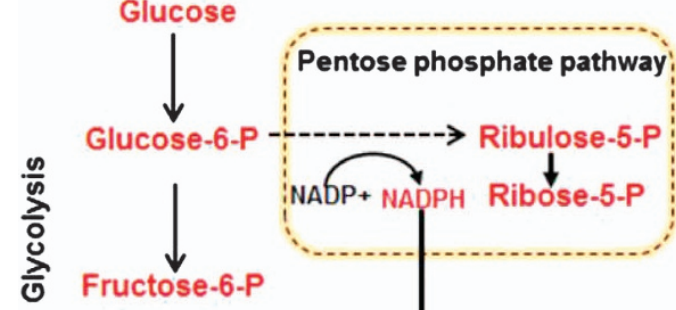

Fructose-1,6-bip

I

$\downarrow$

Lactate

Red $\rightarrow$ Increased Blue - Decreased

Black $\rightarrow$ Not changed 
a
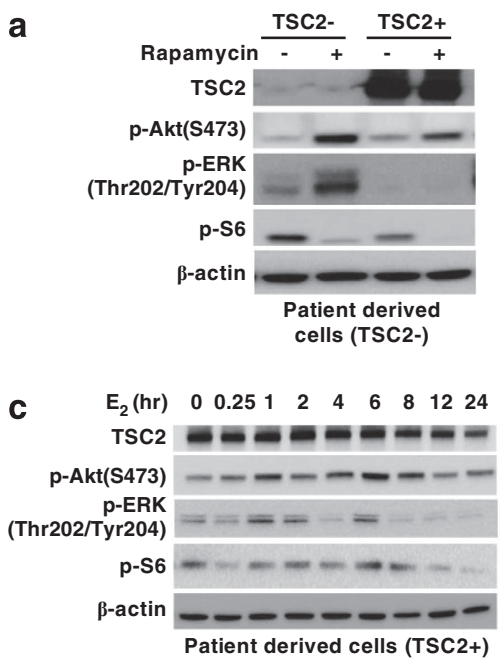

b

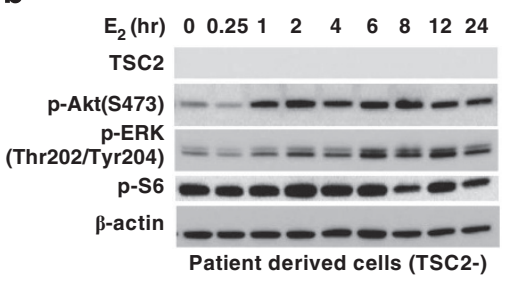

d

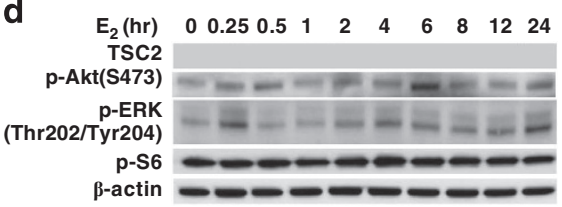

Rat derived cells (TSC2-)

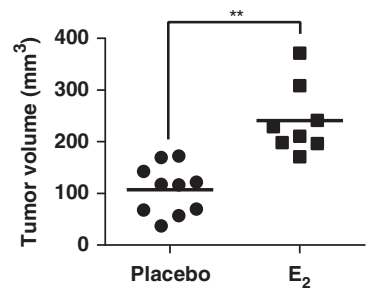

$\mathbf{f}$
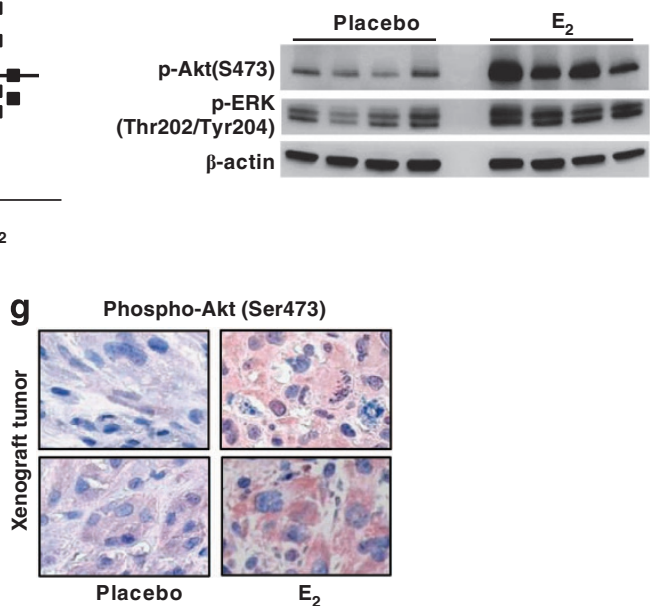

Figure 2 Estradiol reactivates the Akt signaling pathway in vitro and in vivo. (a) Immunoblot analyses of TSC2, phospho-Akt (Ser473), phospho-ERK1/2 (Thr202/Tyr204), phospho-S6 (Ser235/236), and $\beta$-actin in patient-derived TSC2-deficient or TSC2-re-expressing cells treated with control or rapamycin for $12 \mathrm{~h}$. Results are representative of three independent experiments. (b and c) Immunoblot analyses of TSC2, phospho-Akt (S473), phospho-ERK (Thr202/Tyr204), phospho-S6 (Ser235/236), and $\beta$-actin in patient-derived TSC2-deficient or TSC2-re-expressing cells treated with estradiol. Results are representative of three different experiments. (d) Immunoblot analyses of TSC2, phospho-Akt (S473), phospho-ERK (Thr202/Tyr204), phospho-S6 (Ser235/236), and $\beta$-actin in rat-derived Tsc2-deficient cells treated with estradiol. Results are representative of three different experiments. (e) ELT3 cells were subcutaneously injected into female ovariectomized mice implanted with estradiol or placebo pellets. Tumor volume was calculated at week 8 post cell inoculation. (f) Immunoblot analyses of phospho-Akt (S473), phospho-ERK (Thr202/Tyr204), and $\beta$-actin in xenograft tumors from mice treated with estradiol or placebo. $(\mathbf{g})$ Immunohistochemistry of phospho-Akt (Ser473) in xenograft tumors of rat-derived Tsc2-deficient cells from mice treated with estradiol or placebo. Results are representative of five mice in each group. ${ }^{*} P<0.01$

activation due to feedback inhibition mechanism, ${ }^{19}$ these data reveal that $E_{2}$ reactivates Akt pathway in cells lacking TSC2.

\section{Estradiol promotes plasma membrane translocation of glucose transporters GLUT1 or GLUT4 and glucose} uptake in an Akt-dependent manner. Glucose entry into cells is facilitated by proper localization of glucose transporters including GLUT1 and GLUT4 ${ }^{20}$ To examine the impact of $E_{2}$ on GLUT1 and GLUT4 localization, TSC2-deficient LAM patient-derived or rat-derived cells were treated with $E_{2}$ for $24 \mathrm{~h}$. Confocal microscopy showed that $E_{2}$ promoted plasma membrane translocation of GLUT4, but not GLUT1, compared with control in LAM patient-derived cells (Figure 3a). Interestingly, treatment of mTORC1 inhibitor rapamycin led to plasma membrane translocation of GLUT4.
Importantly, $\mathrm{E}_{2}$-promoted membrane localization of GLUT4 was abolished by wortmannin treatment (Figure 3a). Furthermore, Akt inhibitors MK2206 and wortmannin strongly suppressed $\mathrm{E}_{2}$-induced phosphorylation of Akt (S473), but not phosphorylation of ERK or S6, in patient-derived cells (Figure 3b). Moreover, analysis of rat-derived Tsc2-deficient cells showed that rapamycin treatment led to plasma membrane localization of GLUT1 (Figure 3c). Importantly, $E_{2}$ promoted membrane localization of GLUT1, which was abolished by wortmannin treatment (Figure 3c). Immunoblot analysis showed that wortmannin treatment markedly decreased $E_{2}$-induced phosphorylation of Akt (S473), but not phosphorylation of S6 (Figure 3d). Together, these data suggest that Akt specifically mediates the effect of $E_{2}$ on GLUT1 or GLUT4 trafficking in TSC2-deficient cells. 
a

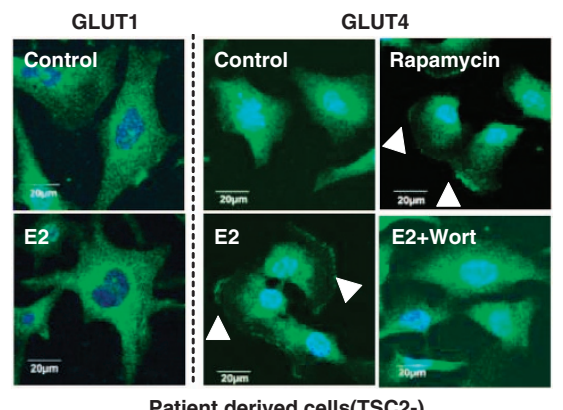

b

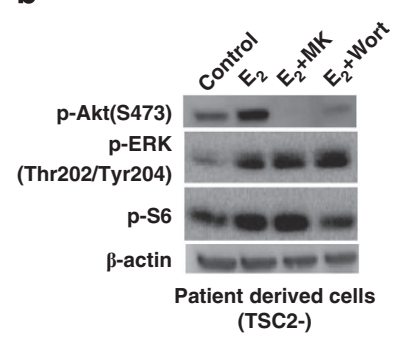

C

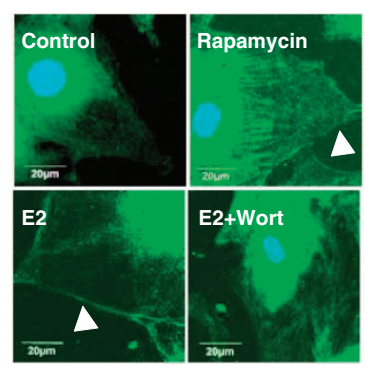

Rat derived cells(TSC2-)

d

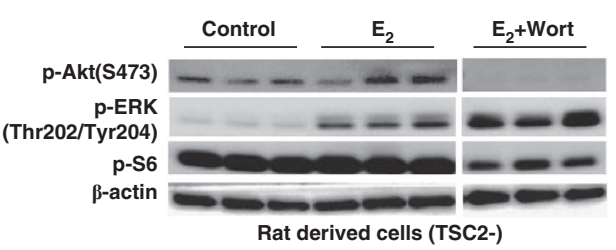

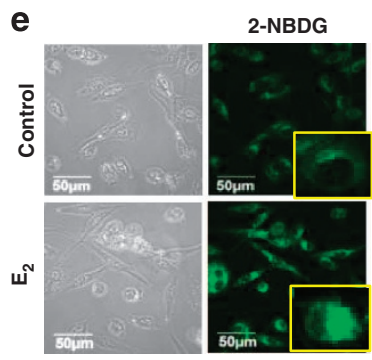

Patient derived cells(TSC2-)

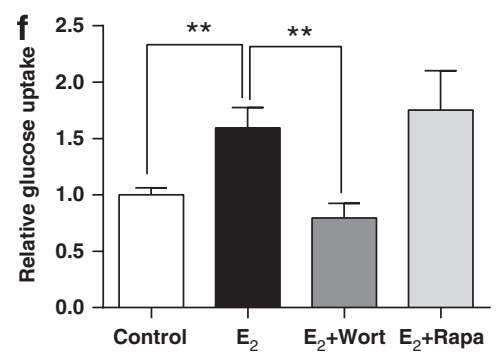

Patient derived cells (TSC2-)

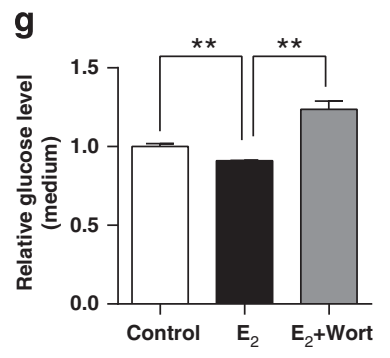

Rat derived cells (TSC2-) h

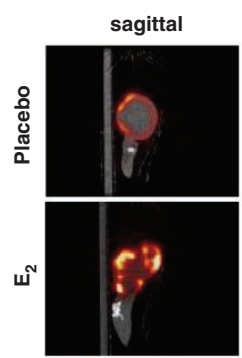

coronal

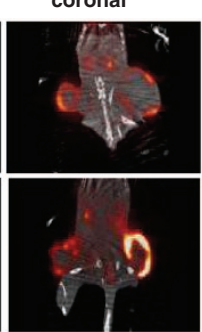

transverse

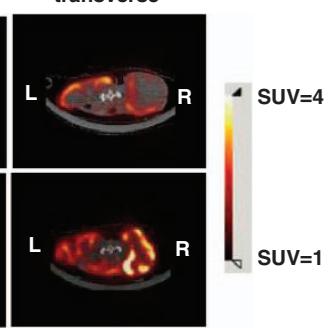

i

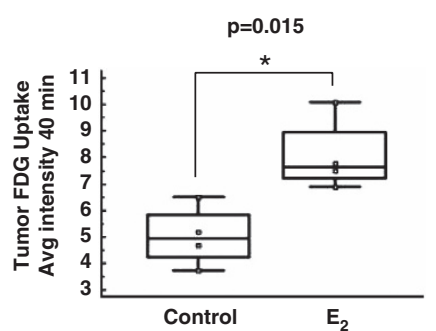

Figure 3 Estradiol enhances GLUT1 and GLUT4 plasma membrane translocation and glucose uptake via PI3K/Akt in TSC2-deficient cells. (a) Patient-derived Tsc2deficient cells were treated with rapamycin $(10 \mathrm{nM})$, wortmannin $(500 \mathrm{nM})$ for $15 \mathrm{~min}$, and then treated with control or estradiol $(10 \mathrm{nM})$ for $12 \mathrm{~h}$. Subcellular localization of GLUT1 and GLUT4 was examined using confocal microscopy. (b) Patient-derived Tsc2-deficient cells treated with estradiol (10 $\mathrm{nM}$ ) at $12 \mathrm{~h}$ in the presence or absence of MK2206 $(2 \mu \mathrm{M})$ or wortmannin $(500 \mathrm{nM})$ for $15 \mathrm{~min}$. Immunoblot analyses of phospho-Akt (Ser473), phospho-ERK1/2 (Thr202/Tyr204), phospho-S6 (Ser235/236), and $\beta$-actin. Results are representative of three independent experiments. (c) Rat-derived Tsc2-deficient cells were treated with rapamycin (10 nM), or wortmannin (1 $\mu \mathrm{M})$ for $15 \mathrm{~min}$, and then treated with control or estradiol $(10 \mathrm{nM})$ for $24 \mathrm{~h}$. Subcellular localization of GLUT1 was examined using confocal microscopy. (d) Patient-derived TSC2-deficient cells treated with estradiol $(10 \mathrm{nM})$ at $12 \mathrm{~h}$ in the presence or absence of wortmannin $(500 \mathrm{nM})$ for 15 min. Immunoblot analyses of phospho-Akt (Ser473), phospho-ERK1/2 (Thr202/Tyr204), phospho-S6 (Ser235/236), and $\beta$-actin. Results are representative of three independent experiments. (e) 2-NBDG uptake was measured in patient-derived cells treated with control or estradiol. (f) Glucose uptake was measured by 2-NBDG fluorescence in patient-derived TSC2-deficient cells treated with estradiol in the presence or absence of wortmannin $(500 \mathrm{nM})$ or rapamycin $(10 \mathrm{nM})$ for $15 \mathrm{~min}$ before treatment. (g) Rat-derived Tsc2-deficient cells were treated with wortmannin $(500 \mathrm{nM})$ for $15 \mathrm{~min}$, and then treated with control or estradiol $(10 \mathrm{nM})$ for $24 \mathrm{~h}$. Extracellular glucose levels were measured in conditioned media. Data were normalized to the control group. (h) Representative images of $\left[{ }^{18} \mathrm{~F}\right] \mathrm{FDG}$-PET/CT scanning of estradiol or placebo-treated mice bearing xenograft tumors of ELT3 cells. (i) The graph indicates the average intensity at 40 min of tumor FDG uptake. ${ }^{*} P<0.05,{ }^{* \star} P<0.01$ 
To determine the impact of $\mathrm{E}_{2}$ on glucose uptake in vitro, we first assessed the direct glucose uptake using 2-NBDG (2-(N-(7-nitrobenz-2-oxa-1,3-diazol-4-yl)amino)-2-deoxyglucose), a fluorescently labeled deoxyglucose analog. Confocal microscopy showed that $E_{2}$ treatment led to higher levels of internalized 2-NBDG relative to vehicle treatment (Figure $3 \mathrm{e}$ ). Fluorescent quantification showed that $E_{2}$ treatment increased 2-NBDG uptake by $60 \%(P<0.01)$ at $30 \mathrm{~min}$ compared with vehicle treatment (Figure $3 f$ ), and this was significantly decreased by wortmannin treatment $(P<0.01)$, but not affected by rapamycin treatment in patient-derived cells (Figure $3 \mathrm{f}$ ). We next examined the rate of glucose consumption in conditioned media. $\mathrm{E}_{2}$ significantly increased glucose consumption by $\sim 10 \%(P<0.01)$ in comparison with vehicle at $24 \mathrm{~h}$ (Figure $3 \mathrm{~g}$ ), indicating that $E_{2}$ enhanced glucose uptake in rat-derived Tsc2-deficient ELT3 cells. Importantly, wortmannin treatment reduced the rate of $\mathrm{E}_{2}$-enhanced glucose uptake (Figure $3 \mathrm{~g}$ ). Collectively, these data demonstrate that Akt specifically mediates the effect of $\mathrm{E}_{2}$ on glucose uptake in cells lacking TSC2 in vitro.

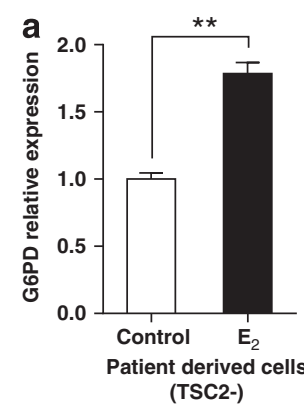

b

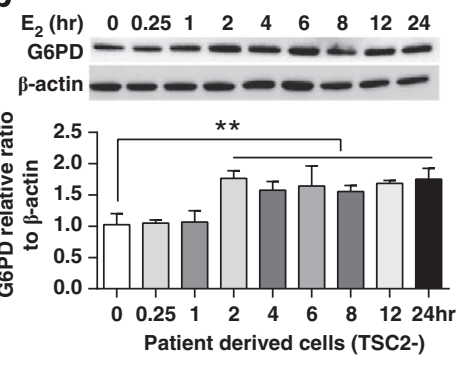

C

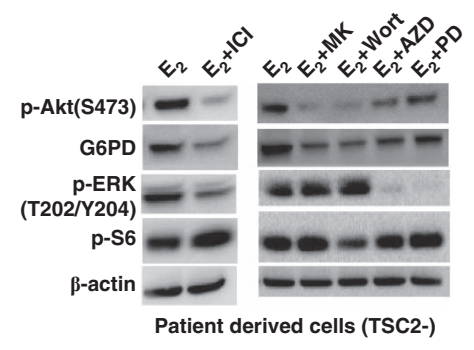

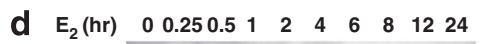
G6PD ----------
$\beta$-actin $=0-0-00-0$

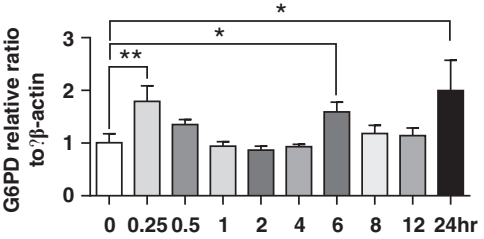
Rat derived cells (TSC2-)

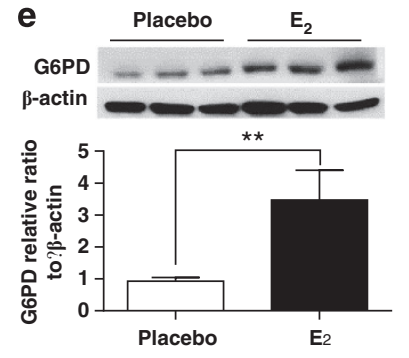

Rat derived (TSC2-) SQ tumors f

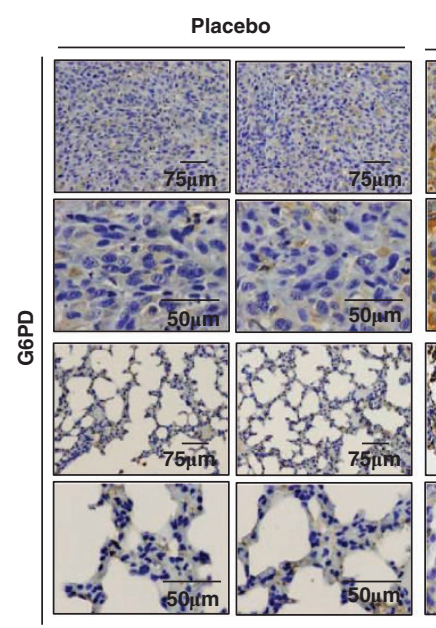

$E_{2}$

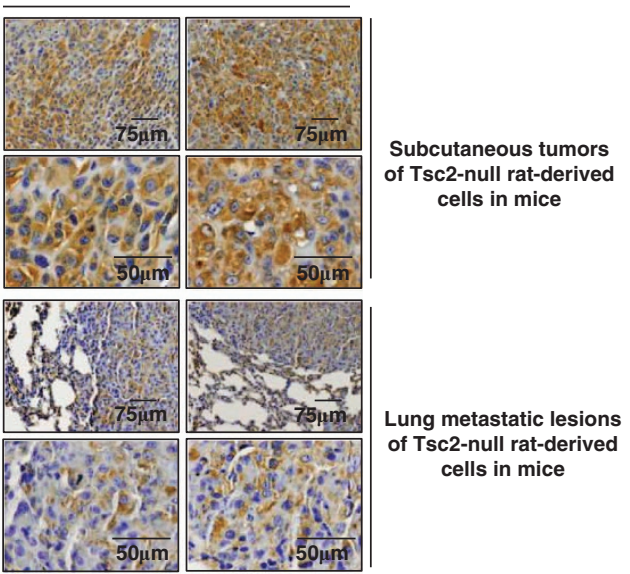

Figure 4 G6PD expression is elevated in Tsc2-deficient cells in vitro and in vivo. (a) Transcript levels of G6PD were measured using real-time RT-PCR in patient-derived TSC2-deficient cells treated with control or estradiol. (b) Immunoblot analyses of G6PD and $\beta$-actin in patient-derived TSC2-deficient cells treated with estradiol. A densitometry analysis of G6PD was performed. Results are representative of three different experiments. (c) Immunoblot analyses of phospho-Akt (Ser473), G6PD, phospho-ERK1/2 (Thr202/Tyr204), phospho-S6 (Ser235/236), and $\beta$-actin in patient-derived TSC2-deficient cells treated with estradiol for $12 \mathrm{~h}$ in the presence or absence of MK2206 $(2 \mu \mathrm{M})$, wortmannin $(500 \mathrm{nM})$, AZD6244 $(500 \mathrm{nM})$, or PD98059 $(50 \mu \mathrm{M})$ for 15 min before treatment. Results are representative of three different experiments. (d) Immunoblot analyses of G6PD and $\beta$-actin in rat-derived Tsc2-deficient cells treated with estradiol at the indicated time points. A densitometry analysis of G6PD was performed. Results are representative of three different experiments. (e) Immunoblot analyses levels of G6PD and $\beta$-actin in xenograft tumors of ELT3 cells. A densitometry analysis of G6PD was performed. Results are representative of three different experiments. (f) Immunohistochemistry of G6PD in xenograft tumors of ELT3 cells and lung metastatic lesions from mice treated with estradiol or placebo. Results are representative of five mice in each group. ${ }^{*} P<0.05,{ }^{* *} P<0.01$ 
To determine whether $\mathrm{E}_{2}$ affects glucose uptake in vivo, $\mathrm{E}_{2}$ or placebo-treated mice bearing established xenograft tumors of Tsc2-deficient ELT3 cells were subjected to $2-\left[{ }^{18} \mathrm{~F}\right]$ Fluoro2-deoxyglucose positron emission tomography/computed tomography (FDG-PET/CT) imaging. The representative images show the $\left[{ }^{18} \mathrm{~F}\right] \mathrm{FDG}-\mathrm{PET} / \mathrm{CT}$ scanning of $\mathrm{E}_{2}$ or placebo-treated mice bearing xenograft tumors of ELT3 cells
(Figure 3h). The FDG uptake in the tumors on the left for both mice appeared to be similar. However, standardized uptake value (SUV) max measured over the volume of the tumor indicated a higher FDG uptake in $\mathrm{E}_{2}\left(\mathrm{SUV}_{\max }=7.54\right.$ (right) and 6.88 (left)) than in the control animal $\left(S_{\text {max }}=4.72\right.$ (right) and 3.74 (left)) (Figure 3i). The average tumor FDG uptake increased by $\sim 50 \%$ in $E_{2}$-treated mice relative to
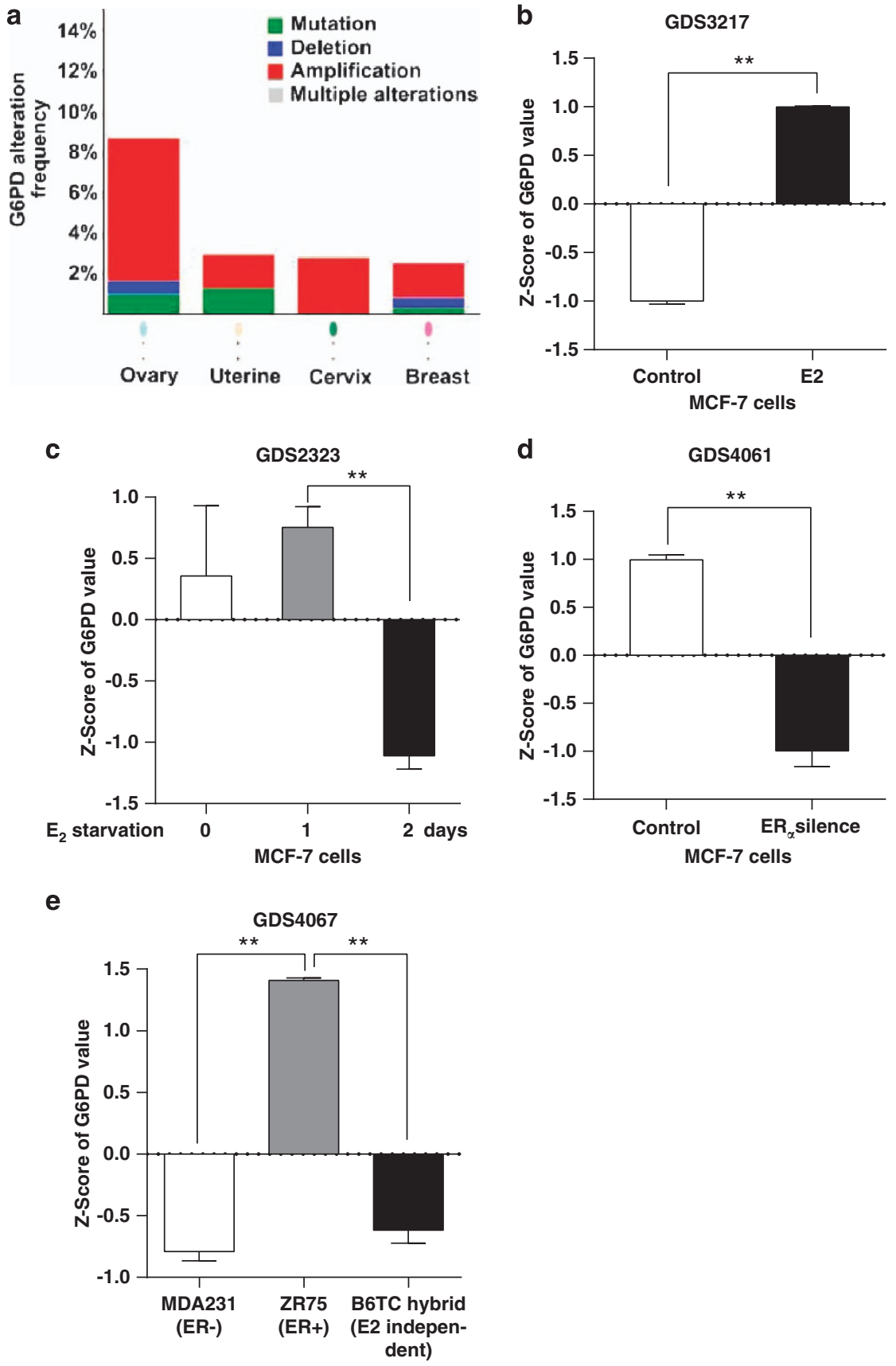

Figure 5 G6PD expression is estradiol-dependent in female cancers. (a) Genomic alterations of G6pd were determined in TCGA-curated female cancers including ovary, uterine, cervix, and breast. ${ }^{23}$ The colored boxes denote various alterations: green, mutation; dark blue, deletion; red, amplification; gray, multiple alterations. (b-e) Levels of G6pd mRNA were determined using cDNA microarray analyses of publicly available microarray data sets. (b) Breast cancer MCF-7 cells were treated with estradiol or control (GEO data set GDS3217). (c) MCF-7 cells were estradiol starved for 0 , 1, or 2 days (GEO data set GDS2323). (d) MCF-7 cells were transfected with estrogen receptor $\alpha$ (ER $\alpha$ )-siRNA (ER $\alpha$ silence) or control-siRNA (control) (GEO data set GDS4061). (e) MDA231 (ER-negative), ZR75 (ER-positive), and B6TC hybrid (estrogen-independent) (GEO data set GDS4067). ${ }^{* \star} P<0.01$ 
placebo-treated mice $(P=0.015$, Figure 3i). These data indicate that $\mathrm{E}_{2}$ enhances glucose uptake by Tsc2-deficient tumor cells in vivo.

Estradiol increases the expression of glucose-6-phosphate dehydrogenase in vitro and in vivo. To explore the impact of $E_{2}$ on the flux of glucose to pentose phosphate pathway at the mechanistic level in TSC2-deficient cells, we first examined the transcript levels of glucose-6-phosphate dehydrogenase (G6PD), the first rate-limiting enzyme of the pentose phosphate pathway. $E_{2}$ treatment increased the transcript levels of G6PD at $24 \mathrm{~h}$ by $\sim$ twofold relative to vehicle control in patient-derived cells $(P<0.05$, Figure $4 a)$. It has been reported that G6PD alternative splicing is one of the regulatory mechanisms responsible for G6PD expression. ${ }^{21,22}$ We performed real-time RT-PCR analysis using primers specific to the pre-mRNA and mature mRNA of G6PD. We found that estradiol treatment did not alter the G6PD mature mRNA/pre-mRNA ratio in LAM patient-derived cells (Supplementary Figure S1). Furthermore, cells stimulated by $E_{2}$ exhibited higher levels of G6PD protein by $\sim$ twofold at $2-24 \mathrm{~h}$ in patient-derived cells $(P<0.01$, Figure 4b). Importantly, the estrogen receptor antagonist ICl 182780 (Faslodex or Fulvestrant) strongly reduced $E_{2}$ increased G6PD protein in patient-derived cells (Figure 4c). To examine whether Akt is a critical mediator of G6PD expression, we treated patient-derived cells with MK-2206 (an allosteric Akt inhibitor), or wortmannin (an irreversible PI3K inhibitor) for $24 \mathrm{~h}$. We found that both inhibitors markedly reduced $\mathrm{E}_{2}$-increased $\mathrm{G6PD}$ protein (Figure $4 \mathrm{c}$ ), further supporting that Akt is a critical component in $E_{2}$ altered glucose metabolism in cells lacking TSC2. Interestingly, MEK/1/2 inhibitors AZD6244 or PD98059 had modest effect on $E_{2}$-enhanced G6PD expression (Figure $4 c$ ). We also found that $E_{2}$ increased the levels of G6PD protein in rat-derived cells within $24 \mathrm{~h}$ (Figure $4 \mathrm{~d}$ ), consistent with the findings in patient-derived cells. Importantly, $\mathrm{E}_{2}$ treatment did not affect the levels of G6PD protein in TSC2-re-expressing patient-derived (Supplementary Figure S2A) or rat-derived cells (Supplementary Figure S2B).

Next, we examined the effect of $\mathrm{E}_{2}$ on G6PD expression in cells lacking TSC2 in vivo. Xenograft tumors of ELT3 cells from $E_{2}$-treated mice exhibited a 3.5-fold increase of G6PD expression relative to placebo treatment $(P<0.01$, Figure $4 \mathrm{e})$.
Immunohistochemistry showed that G6PD accumulation was more evident in xenograft tumors from $E_{2}$-treated mice compared with placebo-treated mice (Figure 4f). Importantly, cells in lung metastatic lesions from $\mathrm{E}_{2}$-treated mice showed abundant accumulation of G6PD (Figure 4f). These data demonstrate that $E_{2}$ enhances the expression of G6PD in cells lacking TSC2 both in vitro and in vivo.

G6PD expression is estradiol dependent in female cancers. We have found that estradiol increased the expression of G6PD in mTORC1 hyperactive cells. To examine the levels of G6PD in other female cancers, we first analyzed the frequency of genomic alterations of G6pd from The Cancer Genome Atlas (TCGA) data set. ${ }^{23}$ Despite the mutation, deletion, and multiple alterations, G6pd amplification frequency was higher in ovary cancer ( $\sim 9 \%)$, cervix cancer $(3 \%)$, uterine cancer $(2 \%)$, and breast cancer $(2 \%)$ (Figure $5 a)$. To examine the impact of $E_{2}$ on the levels of G6pd transcript in breast cancer cells, we analyzed publicly available expression array data sets. $E_{2}$ stimulation significantly increased the transcript levels of G6pd compared with vehicle control in MCF-7 cells (GDS3217 data set) ${ }^{24}$ (Figure $5 b$ ). $E_{2}$ starvation for 2 days significantly decreased the transcript levels of G6pd relative to 1-day $E_{2}$ starvation or regular condition in MCF-7 cells (GDS2323 data set ${ }^{25}$ (Figure 5c). Molecular depletion of ER $\alpha$ reduced the transcript levels of G6pd in MCF-7 cells (GDS4061 data set) ${ }^{26}$ (Figure 5d). Furthermore, ER-positive breast cancer cell line ZR75 displayed higher transcript levels of G6pd relative to ER-negative MDA231 cell line and $E_{2}$-independent B6TC hybrid cell line (GDS4067 data set) ${ }^{27}$ (Figure 5e). Taken together, these data indicate that levels of G6PD are dependent on $E_{2}$ and its cognate receptor in female predominant cancers including breast cancer cells, consistent with our findings in TSC2-deficient cells. Depletion of G6PD attenuates estradiol-enhanced
survival of TSC2-deficient cells in vitro and in vivo. To
determine whether inhibition of G6PD impacts the survival of
ELT3 cells in vitro, we downregulated G6PD using siRNA in
ELT3 cells, achieving $\sim 50 \%$ downregulation (Figure $6 \mathrm{a}$ ).
G6PD knockdown prevented $\mathrm{E}_{2}$-decreased ROS production
in comparison with control siRNA (Figure $6 \mathrm{~b}$ ). Importantly,
G6PD downregulation significantly suppressed $\mathrm{E}_{2}$-enhanced

Figure 6 Depletion of G6PD attenuates estradiol-enhanced survival of Tsc2-deficient cells in vitro and in vivo. (a) Tsc2-deficient cells were transfected with control siRNA or G6PD siRNA for $48 \mathrm{~h}$, and then treated with control or estradiol for $6 \mathrm{~h}$. Levels of G6PD, phospho-S6 (Ser235/236), and $\beta$-actin were assessed by immunoblot. The graph indicates the ratio of G6PD to $\beta$-actin. Results are representative of three different experiments. (b) Tsc2-deficient cells were transfected with control siRNA or G6PD siRNA for $48 \mathrm{~h}$, and then treated with control or estradiol for $24 \mathrm{~h}$. Hydrogen peroxide $(0.5 \mu \mathrm{M})$ was added for $1 \mathrm{~h}$ before measurement. Cellular ROS level was measured with the DCFH-DA. Data were normalized to total cell number. Results are representative of eight sets of independent samples per group from three experiments. (c) Cell death was measured using propidium iodide (PI) exclusion assay. Data were normalized to total cell number. Results are representative of eight sets of independent samples per group from three experiments. (d) Tsc2-deficient cells were treated with 6-AN $(10 \mu \mathrm{M})$ for $1 \mathrm{~h}$, and then treated with control or estradiol for $24 \mathrm{~h}$. G6PD activity was determined. (e) Tsc2-deficient cells were treated with 6-AN $(10 \mu \mathrm{M})$ for $1 \mathrm{~h}$, and then treated with control or estradiol (10 nM) for 2 and $24 \mathrm{~h}$. Cellular NADPH level was measured. Data were normalized to total protein level. Results are representative of three sets of independent samples per group from three experiments. (f) Tsc2-deficient cells were treated with 6-AN $(10 \mu \mathrm{M})$ for $1 \mathrm{~h}$, and then treated with control or estradiol $(10 \mathrm{nM})$ for $24 \mathrm{~h}$. Cellular ROS level was measured with the DCFH-DA. Data were normalized to cell number. Results are representative of eight sets of independent samples per group from three experiments. (g) Tsc2-deficient cells were treated with 6 -AN (10 $\mu \mathrm{M})$ for $1 \mathrm{~h}$, and then treated with control or estradiol $(10 \mathrm{nM})$ for $24 \mathrm{~h}$. Cell death was measured using the PI exclusion assay. Data were normalized to cell number. Results are representative of eight sets of independent samples per group from three experiments. (h) Female CB17 SCID mice were supplemented with estradiol for 1 week, and then treated with 6-AN or vehicle for 2 days. ELT3-luciferase cells were treated with 6 -AN for $18 \mathrm{~h}$, and then injected intravenously into mice ( $n=5 /$ group). Lung colonization was measured using bioluminescence at $0.5,6$, and $24 \mathrm{~h}$ after injection. Representative images are shown. Total photon flux/second present in the chest regions in estradiol $(n=5)$ and estradiol plus 6-AN-treated $(n=5)$ animals. (i) Scheme of estradiol-promoted pentose phosphate pathway addiction in TSC2-deficient cells. ${ }^{*} P<0.05$, ${ }^{\star \star} P<0.01$ 
survival of Tsc2-deficient ELT3 cells after $\mathrm{H}_{2} \mathrm{O}_{2}$ treatment (Figure 6c).

To inhibit G6PD pharmacologically, we treated Tsc2deficient cells with 6-AN, an inhibitor of G6PD and pentose phosphate pathway. 6-AN treatment significantly decreased
$\mathrm{E}_{2}$-induced G6PD activity $(P<0.01$, Figure $6 \mathrm{~d}), \mathrm{E}_{2}$-enhanced cellular level of NADPH $(P<0.01$, Figure $6 e)$, and $\mathrm{E}_{2}$-reduced ROS production ( $P<0.05$, Figure 6f). Importantly, 6-AN treatment significantly suppressed $E_{2}$-enhanced survival of ELT3 cells after $\mathrm{H}_{2} \mathrm{O}_{2}$ treatment $(P<0.05$, Figure $6 \mathrm{~g})$. a
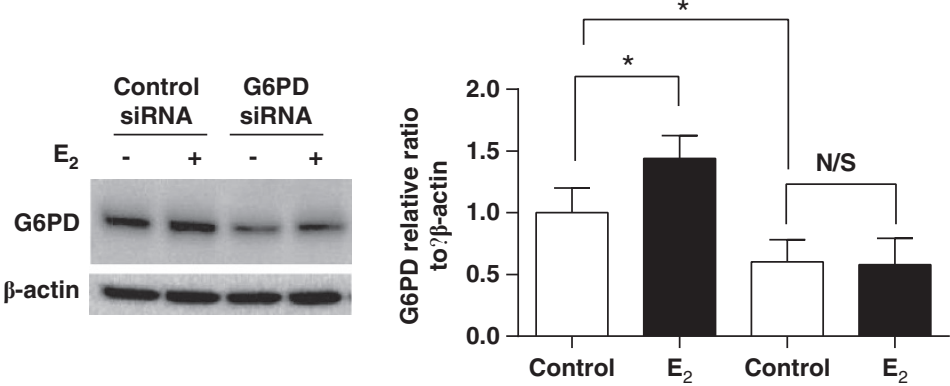

C

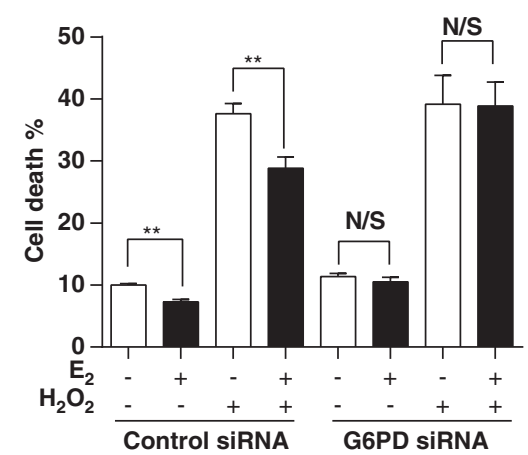

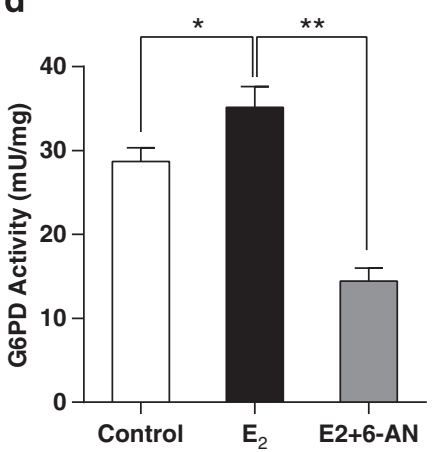

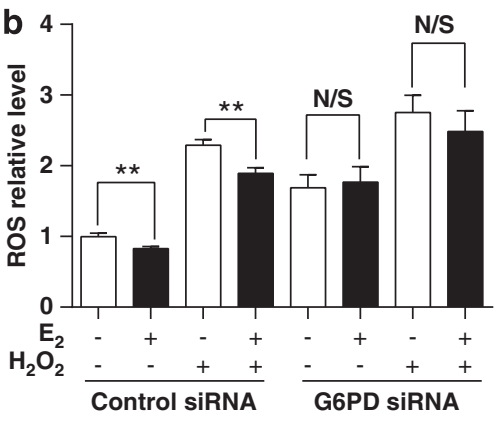

e

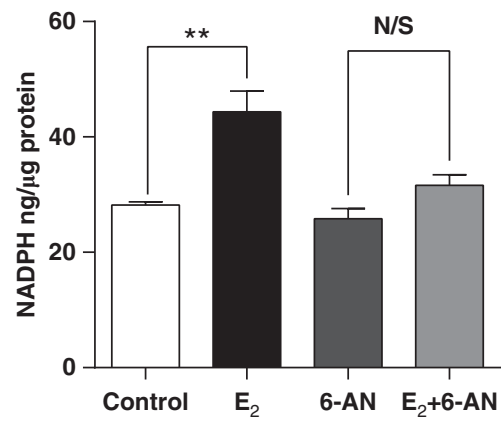

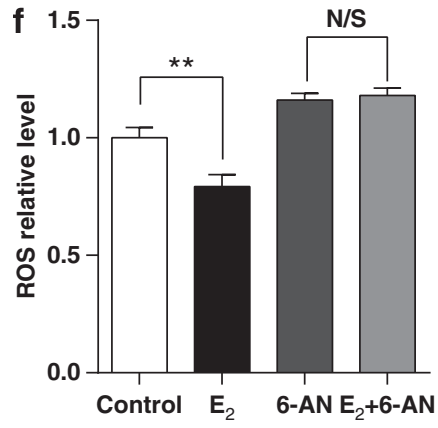

9

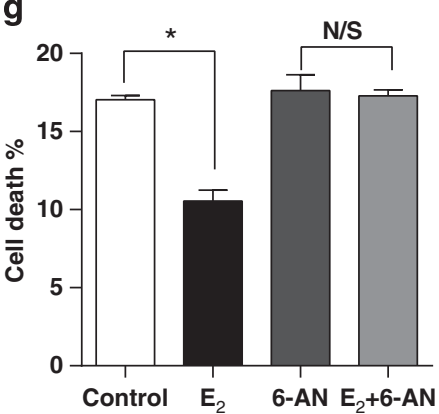

h

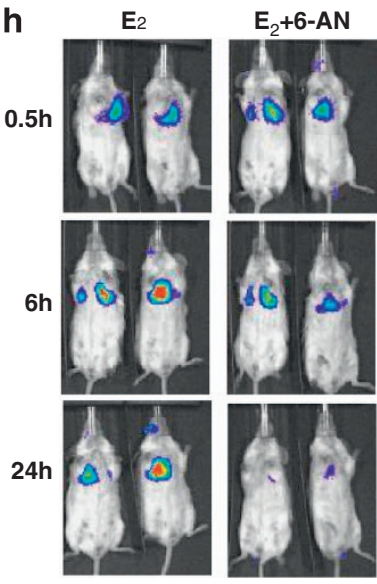

i

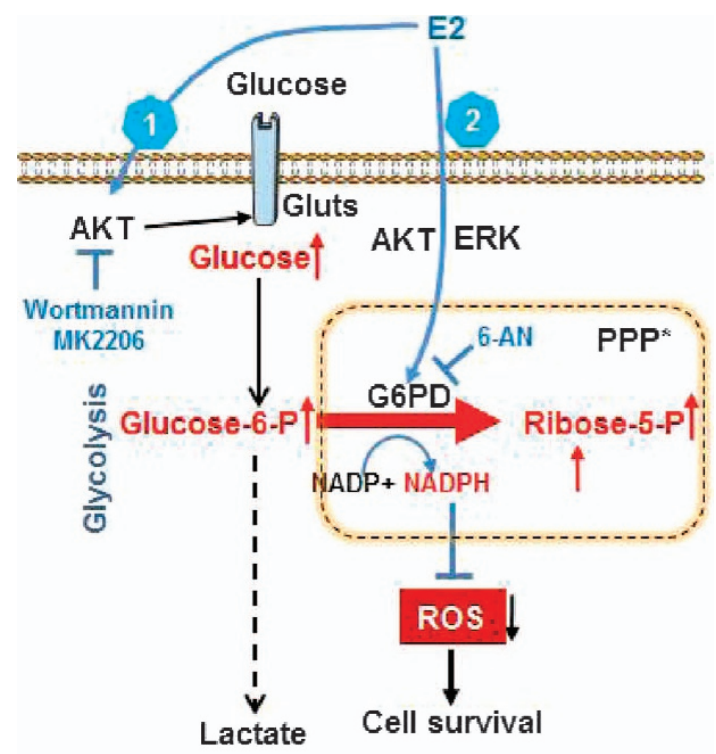

${ }^{\star} \mathrm{PPP} \rightarrow$ Pentose phosphate pathway 
These data indicate that depletion of G6PD attenuates $\mathrm{E}_{2}$-enhanced survival of ELT3 cells in vitro.

To investigate further the role of G6PD on the survival of ELT3 cells in vivo, ELT3 luciferase cells ${ }^{28}$ were intravenously injected into mice treated with $\mathrm{E}_{2}$ alone or $\mathrm{E}_{2}$ plus 6-AN. At 0.5 and $6 \mathrm{~h}$ post cell inoculation, similar levels of bioluminescence were observed in the chest regions of all mice. At $24 \mathrm{~h}$, the bioluminescence in the chest regions of the $E_{2}$ plus 6 -AN-treated mice was decreased by $\sim 80 \%$ as compared with that in the $\mathrm{E}_{2}$-treated mice $(P<0.05$, Figure $6 \mathrm{~h})$. These data support a model in which inhibition of G6PD attenuates $\mathrm{E}_{2}$-enhanced survival of Tsc2-deficient cells in vivo.

\section{Discussion}

LAM is a female predominant lung disease characterized by the abnormal proliferation of smooth muscle cells and progressive cyst formation that can lead to respiratory failure. $^{1-3}$ The gender specificity of LAM suggests that estradiol may contribute to disease progression, whereas mTORC1, which is hyperactive in LAM cells, is a master regulator of cellular metabolism. However, the role of estradiol in regulating the metabolism in Tsc2-deficient cells has not been extensively investigated. In this study, we identified an estradiol-enhanced glucose and pentose phosphate pathway signature in Tsc2-deficient rat uterine leiomyoma-derived ELT3 cells in vitro. Estradiol treatment led to increased cellular NADPH and decreased ROS and enhanced cell survival under oxidative stress. Estradiol also induced plasma membrane translocation of GLUT1 or GLUT4 and increased glucose uptake in a PI3K/Akt-dependent manner. ${ }^{18} \mathrm{~F}-\mathrm{FDG}-\mathrm{PET} / \mathrm{CT}$ imaging showed enhanced glucose uptake in xenograft tumors from estradiol-treated mice. Depletion of G6PD, a rate-limiting enzyme for the pentose phosphate pathway, suppressed estradiol-enhanced survival of Tsc2-deficient cells in vitro and in vivo. Collectively, these data indicate that estradiol promotes glucose metabolism through the pentose phosphate pathway in cells with $\mathrm{mTORC} 1$ hyperactivation and enhances cell survival under oxidative stress.

Alterations in cellular energy metabolism are a hallmark of cancer, ${ }^{6}$ and there are many indications that metabolic reprogramming is particularly critical for the survival of Tsc2-deficient cells. Glucose addiction of Tsc2-deficient cells has been reported, ${ }^{8}$ suggesting that glucose metabolism is essential for the survival of Tsc2-deficient cells. TSC2 deficiency leads to increased transcript levels of glucose metabolism genes. ${ }^{10}$ Cells with mTORC1 activation express high levels of glycolytic proteins PKM2. ${ }^{11}$ Somewhat surprisingly, however, the $\mathrm{mTORC} 1$ inhibitor rapamycin reduces lactate production but does not affect cellular ATP levels in $T s c 2^{-1-}$ MEF cells. ${ }^{9}$ Together, these reports highlight connections between cellular metabolic alterations and glucose utilization that is likely to impact TSC2-deficient LAM cells.

${ }^{18} \mathrm{~F}$-FDG-PET scanning has been performed in LAM patients. One case report described a strong FDG uptake in pulmonary $\mathrm{LAM}^{29}$ Moreover, Young et al. ${ }^{30}$ performed FDG-PET scanning in 12 LAM patients and FDG-PET was negative for all patients. Reasons for the negativity of FDG-PET in LAM patients may include: (1) the sensitivity of PET detection because of the diffused infiltration of LAM cells; (2) emphysema-like destruction of lung parenchyma; ${ }^{1}$ (3) downregulation and cytoplasmic localization of glucose transporters in cells lacking TSC2; ${ }^{31}$ (4) glucose uptake and PET positivity may be cyclical, depending on circulating estrogen levels.

We previously showed that estradiol promotes the metastasis of Tsc2-deficient ELT3 tumors in a MEK1/2-dependent manner. ${ }^{28}$ Here, we report that estradiol promotes glucose metabolism via the pentose phosphate pathway in TSC2deficient cells, associated with a MEK1/2-independent but PI3K/ Akt-dependent plasma membrane translocation of GLUT1 or GLUT4. This is particularly interesting, because it has been previously demonstrated that Glut1 and Glut4 are localized in the cytoplasm but not in the plasma membrane in Tsc2-deficient cells, ${ }^{31}$ which may limit their ability to proliferate especially under conditions of bioenergetic stress. Our finding that estradiol is sufficient to restore membrane localization of the GLUT1 or GLUT4 transporter and enhance glucose uptake may, therefore, represent a key pathogenic mechanism underlying the female predominance of LAM (Figure 6i).

LAM can lead to respiratory failure and death. ${ }^{1-3}$ The recent MILES trial demonstrated that the mTORC1 inhibitor Sirolimus stabilizes lung function in women with LAM. However, lung function decline resumed upon drug discontinuation. ${ }^{32}$ Therefore, despite many advances in the clinical care of women with LAM, there remains a critical need for improved therapeutic options. The fact that estradiol promotes glucose utilization and cell survival via the pentose phosphate pathway suggests that inhibiting the PPP could selectively inhibit estrogen-induced cell survival. Consistent with this hypothesis, we found that 6-AN blocked estrogeninduced survival both in vivo and in vitro, suggesting a novel therapeutic approach for LAM. Our data suggest that inhibiting estrogen-dependent cellular metabolic pathways could block the pro-survival effects of estrogen on LAM cells, without the need to ablate the entire hormonal signaling axis. In the long term, it is possible that metabolically focused strategies in LAM could have preferable side effect profiles compared with hormonal ablation in terms of bone health and other parameters; clearly additional pre-clinical and clinical studies will be needed to test this concept.

\section{Materials and Methods}

Cell line and culture. Eker rat uterine leiomyoma-derived cells (ELT3), ${ }^{14,15}$ ELT3 luciferase-expressing cells, ${ }^{28}$ and LAM patient-derived cells (developed from a sporadic LAM-associated renal angiomyolipoma cells carrying biallelic mutations of the TSC2 gene $^{33}$ ) were cultured in IIA complete medium supplemented with $10 \%$ FBS. Prior to estradiol stimulation, cells were starved in serum-free and phenol red-free IIA media for $24 \mathrm{~h}$.

Antibodies and chemicals. The following chemicals were used: 17-betaestradiol, wortmannin and DAPI (Sigma-Aldrich, St. Louis, MO, USA), rapamycin (L C Laboratories, Woburn, MA, USA), PD98059 (Cell Signaling Technologies, Danvers, MA, USA), MK2206 (Active Biochem, Maplewood, NJ, USA), and AZD6244 (L C Laboratories). Antibodies included phospho-ERK1/2 (T202/Y204), phospho-S6 (S235/236), phospho-Akt (S473) and TSC2 (Cell Signaling Technologies), G6PD and GLUT1 (H-43) (Santa Cruz Biotechnology, Dallas, TX, USA), GLUT4 and $\beta$-actin (Sigma-Aldrich), and Alexa Fluor 488 Goat AntiRabbit IgG (Invitrogen, Grand Island, NY, USA).

Metabolomic profiling. Cell pellets were submitted to Metabolon Inc. (Durham, NC, USA) for sample extraction and analysis. Briefly, Metabolon 
performed cold methanol extraction of cell pellets and these extracts were split into three aliquots. These aliquots were processed and characterized by one of the three analytical methods previously described. ${ }^{34,35}$

Cellular NADPH quantification. Cells were seeded in 12-well plates, treated with siRNA or inhibitors, and then stimulated with control or estradiol $(10 \mathrm{nM})$. Cells $\left(1 \times 10^{5}\right)$ were harvested and lysates were extracted with $200 \mu \mathrm{l}$ of extraction buffer following the manufacture's instruction. Levels of NADPH were measured using the NADP/NADPH Assay kit (Abcam, Cambridge, MA, USA) and normalized to total cellular proteins.

Quantification of ROS. Cells were seeded in 96-well plates and incubated with $50 \mu \mathrm{M}$ DCFH-DA in $1 \times$-DPBS for $45 \mathrm{~min}$ at $37^{\circ} \mathrm{C}$. Fluorescence was read at $485 \mathrm{~nm} / 525 \mathrm{~nm}$. Levels of cellular ROS were normalized to the total number of cells.

Measurement of cell survival. Cells were plated in 96-well plates, incubated with propidium iodide $(5 \mu \mathrm{M})$ in $100 \mu \mathrm{l} 1 \times$-DPBS for $30 \mathrm{~min}$ at $37^{\circ} \mathrm{C}$. Fluorescence was read at $530 \mathrm{~nm} / 620 \mathrm{~nm}$. Data were represented as percentage of dead cells relative to the total number of cells. Cell growth was measured using crystal violet assay.

Immunoblotting. Cells were lysed in M-PER buffer (Pierce, Rockford, IL, USA) supplemented with protease inhibitors and phosphatase inhibitor cocktails. Cleared cell lysates were obtained by centrifugation at 14000 r.p.m. for $10 \mathrm{~min}$ at $4{ }^{\circ} \mathrm{C}$ and then subjected to immunoblotting.

Animal studies. All animal work was performed in accordance with protocols approved by the Institutional Animal Care and Use CommitteeChildren Hospital Boston. For xenograft tumor establishment, 1 week before cell inoculation, mice were implanted with estradiol pellets (90-day release, $2.5 \mathrm{mg} /$ pellet, Innovative Research of America, Sarasota, FL, USA) or placebo pellets. Two million ELT3 cells were inoculated bilaterally into the posterior back region of the mice. Mice bearing subcutaneous tumors $\left(\sim 250 \mathrm{~mm}^{3}\right)$ underwent FDG-PET scanning. For the intravenous model, 0.5 million ELT3 luciferase cells in a volume of $100 \mu$ l were injected intravenously into the tail vein of the CB-17 SCID mice pretreated with estradiol $(500 \mathrm{nM}$ in drinking water) for 2 days before cell injection.

Immunohistochemistry. Sections were deparaffinized, incubated with primary antibodies and biotinylated secondary antibodies, and counterstained with Gill's Hematoxylin.

Immunofluorescence. Cells were plated on glass coverslips, serum starved overnight, treated with rapamycin $(10 \mathrm{nM})$ or wortmannin $(500 \mathrm{nM})$ for $15 \mathrm{~min}$, and then stimulated with control or estradiol $(10 \mathrm{nM})$ for 12 or $24 \mathrm{~h}$. Cells were fixed with $50 \%$ methanol plus $50 \%$ acetone for 2 min, blocked in $1 \%$ BSA/PBS/Tween $20(0.05 \%)$ for $30 \mathrm{~min}$, incubated with primary antibody for $1 \mathrm{~h}$ and then secondary antibodies for $1 \mathrm{~h}$. Images were captured with a FluoView FV-10i Olympus Laser Point Scanning Confocal Microscope, Olympus (Center Valley, PA, USA).

2-NBDG uptake. 2-[N-(7-nitrobenz-2-oxa-1,3-diazol-4-yl)amino]-2-deoxyglucose (2-NBDG, Cayman Chemical, Ann Arbor, MI, USA), a glucose analog fluorescently labeled at the two position, is a substrate for glucose transporters. ${ }^{36}$ Cells were cultured in IIA medium with $10 \%$ FBS, starved with serum-free and phenol-free IIA medium overnight, pretreated with inhibitors for $15 \mathrm{~min}$, and then stimulated with $E_{2}(10 \mathrm{nM})$ for $24 \mathrm{~h}$. Medium was changed to phenol-free serumfree glucose-free DMEM with $50 \mu \mathrm{mol} / / 2-N B D G$ for $30 \mathrm{~min}$. Internalization of 2-NBDG was monitored using confocal microscopy. 2-NBDG uptake was quantified using fluorescence intensity and normalized to control.

Glucose assay. Cells were seeded in 12-well plates, treated with inhibitors, and then stimulated with control or estradiol $(10 \mathrm{nM})$. Conditioned media was collected and subjected to glucose quantification using the Glucose (HK) Assay Kit (Sigma-Aldrich).

${ }^{18}$ F-FDG-PET imaging. Mice bearing subcutaneous tumors $\left(\sim 250 \mathrm{~mm}^{3}\right)$ were intravenously injected with $150 \mu \mathrm{Ci}$ of $\left[{ }^{18} \mathrm{~F}\right] \mathrm{FDG}$. After $30 \mathrm{~min}$, animals were anesthetized with $2 \%$ isofluorane, and imaged for 15 min using a small animal
PET/CT scanner (eXplore Vista, GE Healthcare, Waukesha, WI, USA). Images were reconstructed using Fourier rebinning (FORE) and ordered subsets expectation maximization algorithm with 16 subsets and 2 iterations. The voxel dimensions of the reconstructed images were $0.39 \times 0.39 \times 0.78 \mathrm{~mm}^{3}$. [ $\left.{ }^{18} \mathrm{~F}\right] \mathrm{FDG}$ uptake in each mouse normalized to the body weight and injected FDG dose, and was presented as SUV.

TCGA data analysis. Genomic alterations of G6pd data for all TCGA cases were analyzed from TCGA data sets obtained from the cBioPortal for Cancer Genomics (http://www.cbioportal.org/public-portal/index.do)

Gene expression analysis. The publicly available microarray GEO data sets (www.ncbi.nlm.nih.gov/geo/) were collected. The Z-score of G6pd mRNA was used for data analysis.

siRNA transfection. Control-siRNA $(50 \mathrm{nM})$ or G6PD-siRNA (Dharmacon, Pittsburgh, PA, USA) were transfected in cells using TransIT-TKO reagent (Mirus, Madison, WI, USA). Cells were harvested at 48-60 h post transfection.

G6PD activity assay. Cells were seeded in 12-well plates, treated with inhibitors, and then stimulated with control or estradiol $(10 \mathrm{nM})$. Cells $\left(1 \times 10^{5}\right)$ were collected and lysates were extracted with $200 \mu$ l of extraction buffer following the manufacture's protocol. G6PD activity was quantified using G6PD Activity Colorimetric Assay kit (Biovision, Milpitas, CA, USA). G6PD activity was normalized to total protein levels.

Bioluminescent reporter imaging. Ten minutes before imaging, animals were injected with luciferin (Xenogen, Waltham, MA, USA) $(120 \mathrm{mg} / \mathrm{kg}$, i.p.). Bioluminescent signals were recorded using the Xenogen IVIS System. Total photon flux of the chest area was analyzed. ${ }^{28}$

Statistical analyses. All data are shown as mean \pm S.E.M. Measurements at single time points were analyzed by ANOVA and, if they demonstrated significance, were further analyzed by a two-tailed $t$-test. All statistical tests were conducted using GraphPad Prism 6.0 (GraphPad Software, San Diego, CA, USA). $P<0.05$ was used to define statistical significance.

\section{Conflict of Interest}

The authors declare no conflict of interest.

Acknowledgements. We are grateful for Dr. C Walker (Texas A\&M Health Science Center) for providing ELT3 cells. This study is supported by The LAM Foundation, The Adler Foundation, The LAM Treatment Alliance, the National Institute of Diabetes and Digestive and Kidney Diseases, and the National Heart Lung and Blood Institute to EPH, The LAM Foundation grant and NIH Grant GM51405 to JB, and the National Heart Lung and Blood Institute (HL98216) to JJY. $X G$ is a LAM Foundation fellow.

1. Henske EP, McCormack FX. Lymphangioleiomyomatosis-a wolf in sheep's clothing. $J$ Clin Investig 2012; 122: 3807-3816.

2. McCormack FX, Travis WD, Colby TV, Henske EP, Moss J. Lymphangioleiomyomatosis: calling it what it is: a low-grade, destructive, metastasizing neoplasm. Am J Respir Crit Care Med 2012; 186: 1210-1212.

3. Moss J. Focus on lymphangioleiomyomatosis. introduction. Lymphatic Res Biol 2010; 8: 3.

4. Carsillo T, Astrinidis A, Henske EP. Mutations in the tuberous sclerosis complex gene TSC2 are a cause of sporadic pulmonary lymphangioleiomyomatosis. Proc Natl Acad Sci USA 2000; 97: 6085-6090.

5. Karbowniczek M, Astrinidis A, Balsara BR, Testa JR, Lium JH, Colby TV et al. Recurrent lymphangiomyomatosis after transplantation: genetic analyses reveal a metastatic mechanism. Am J Respir Crit Care Med 2003; 167: 976-982.

6. Hanahan D, Weinberg RA. Hallmarks of cancer: the next generation. Cell 2011; 144: 646-674.

7. Warburg O. On the origin of cancer cells. Science 1956; 123: 309-314.

8. Inoki K, Zhu T, Guan KL. TSC2 mediates cellular energy response to control cell growth and survival. Cell 2003; 115: 577-590.

9. Choo AY, Kim SG, Vander Heiden MG, Mahoney SJ, Vu H, Yoon SO et al. Glucose addiction of TSC null cells is caused by failed mTORC1-dependent balancing of metabolic demand with supply. Mol Cell 2010; 38: 487-499. 
10. Duvel K, Yecies JL, Menon S, Raman P, Lipovsky Al, Souza AL et al. Activation of a metabolic gene regulatory network downstream of mTOR complex 1. Mol Cell 2010; 39: 171-183.

11. Sun $Q$, Chen $X$, Ma J, Peng H, Wang F, Zha $X$ et al. Mammalian target of rapamycin up-regulation of pyruvate kinase isoenzyme type $\mathrm{M} 2$ is critical for aerobic glycolysis and tumor growth. Proc Natl Acad Sci USA 2011; 108: 4129-4134.

12. Parkhitko AA, Priolo C, Coloff JL, Yun J, Wu JJ, Mizumura K et al. Autophagy-dependent metabolic reprogramming sensitizes TSC2-deficient cells to the antimetabolite 6-aminonicotinamide. Mol Cancer Res MCR 2014; 12: 48-57.

13. Polimeni M, Voena C, Kopecka J, Riganti C, Pescarmona G, Bosia A et al. Modulation of doxorubicin resistance by the glucose-6-phosphate dehydrogenase activity. Biochem $J$ 2011; 439: 141-149.

14. Howe SR, Gottardis MM, Everitt JI, Goldsworthy TL, Wolf DC, Walker C. Rodent model of reproductive tract leiomyomata. Establishment and characterization of tumor-derived cell lines. Am J Pathol 1995; 146: 1568-1579.

15. Howe SR, Gottardis MM, Everitt JI, Walker C. Estrogen stimulation and tamoxifen inhibition of leiomyoma cell growth in vitro and in vivo. Endocrinology 1995; 136: 4996-5003.

16. Gu X, Yu JJ, llter D, Blenis N, Henske EP, Blenis J. Integration of mTOR and estrogenERK2 signaling in lymphangioleiomyomatosis pathogenesis. Proc Natl Acad Sci USA 2013; 110: 14960-14965.

17. Finlay GA, Hunter DS, Walker CL, Paulson KE, Fanburg BL. Regulation of PDGF production and ERK activation by estrogen is associated with TSC2 gene expression. Am J Physiol Cell Physiol 2003; 285: C409-C418.

18. Finlay GA, York B, Karas RH, Fanburg BL, Zhang $\mathrm{H}$, Kwiatkowski DJ et al. Estrogeninduced smooth muscle cell growth is regulated by tuberin and associated with altered activation of platelet-derived growth factor receptor-beta and ERK-1/2. J Biol Chem 2004; 279: 23114-23122.

19. Manning BD, Logsdon MN, Lipovsky Al, Abbott D, Kwiatkowski DJ, Cantley LC. Feedback inhibition of Akt signaling limits the growth of tumors lacking Tsc2. Genes Dev 2005; 19 : 1773-1778.

20. Faulds MH, Zhao C, Dahlman-Wright K, Gustafsson JA. The diversity of sex steroid action: regulation of metabolism by estrogen signaling. J Endocrinol 2012; 212: 3-12.

21. Tao H, Szeszel-Fedorowicz W, Amir-Ahmady B, Gibson MA, Stabile LP, Salati LM. Inhibition of the splicing of glucose-6-phosphate dehydrogenase precursor mRNA by polyunsaturated fatty acids. J Biol Chem 2002; 277: 31270-31278.

22. Hong $X$, Song $R$, Song $H$, Zheng $T$, Wang J, Liang $Y$ et al. PTEN antagonises Tcl1/hnRNPK-mediated G6PD pre-mRNA splicing which contributes to hepatocarcinogenesis. Gut 2013; e-pub ahead of print 18 December 2013; doi:10.1136/gutjnl-2013-305302.

23. Hanauer DA, Rhodes DR, Sinha-Kumar C, Chinnaiyan AM. Bioinformatics approaches in the study of cancer. Curr Mol Med 2007; 7: 133-141.

24. Lin CY, Vega VB, Thomsen JS, Zhang T, Kong SL, Xie M et al. Whole-genome cartography of estrogen receptor alpha binding sites. PLoS Genet 2007; 3: e87.

25. Coser KR, Chesnes J, Hur J, Ray S, Isselbacher KJ, Shioda T. Global analysis of ligand sensitivity of estrogen inducible and suppressible genes in MCF7/BUS breast cancer cells by DNA microarray. Proc Natl Acad Sci USA 2003; 100: 13994-13999.
26. Al Saleh S, Al Mulla F, Luqmani YA. Estrogen receptor silencing induces epithelial to mesenchymal transition in human breast cancer cells. PloS One 2011; 6: e20610.

27. Mukhopadhyay KD, Bandyopadhyay A, Chang TT, Elkahloun AG, Cornell JE, Yang J et al. Isolation and characterization of a metastatic hybrid cell line generated by ER negative and ER positive breast cancer cells in mouse bone marrow. PloS One 2011; 6: e20473.

28. Yu JJ, Robb VA, Morrison TA, Ariazi EA, Karbowniczek M, Astrinidis A et al. Estrogen promotes the survival and pulmonary metastasis of tuberin-null cells. Proc Natl Acad Sci USA 2009; 106: 2635-2640.

29. Pandit N, Yeung HW. F-18 FDG uptake in pulmonary lymphangioleiomyomatosis. Clin Nuclear Med 2001; 26: 1050-1051.

30. Young LR, Franz DN, Nagarkatte P, Fletcher CD, Wikenheiser-Brokamp KA, Galsky MD et al. Utility of [18F]2-fluoro-2-deoxyglucose-PET in sporadic and tuberous sclerosis-associated lymphangioleiomyomatosis. Chest 2009; 136: 926-933.

31. Jiang X, Kenerson H, Aicher L, Miyaoka R, Eary J, Bissler J et al. The tuberous sclerosis complex regulates trafficking of glucose transporters and glucose uptake. Am J Pathol 2008; 172: 1748-1756.

32. McCormack FX, Inoue Y, Moss J, Singer LG, Strange C, Nakata K et al. Efficacy and safety of sirolimus in lymphangioleiomyomatosis. N Engl J Med 2011; 364: 1595-1606.

33. Yu J, Astrinidis A, Howard S, Henske EP. Estradiol and tamoxifen stimulate LAMassociated angiomyolipoma cell growth and activate both genomic and nongenomic signaling pathways. Am J Physiol Lung Cell Mol Physiol 2004; 286: L694-L700.

34. Evans AM, DeHaven CD, Barrett T, Mitchell M, Milgram E. Integrated, nontargeted ultrahigh performance liquid chromatography/electrospray ionization tandem mass spectrometry platform for the identification and relative quantification of the smallmolecule complement of biological systems. Anal Chem 2009; 81: 6656-6667.

35. Dehaven CD, Evans AM, Dai H, Lawton KA. Organization of GC/MS and LC/MS metabolomics data into chemical libraries. J cheminform 2010; $2: 9$.

36. O'Neil RG, Wu L, Mullani N. Uptake of a fluorescent deoxyglucose analog (2-NBDG) in tumor cells. Mol Imaging Biol 2005; 7: 388-392.

(i) (3) $\odot$ Cell Death and Disease is an open-access journal published by Nature Publishing Group. This work is licensed under a Creative Commons Attribution-NonCommercialNoDerivs 3.0 Unported License. The images or other third party material in this article are included in the article's Creative Commons license, unless indicated otherwise in the credit line; if the material is not included under the Creative Commons license, users will need to obtain permission from the license holder to reproduce the material. To view a copy of this license, visit http://creativecommons.org/ licenses/by-nc-nd/3.0/

Supplementary Information accompanies this paper on Cell Death and Disease website (http://www.nature.com/cddis) 